\title{
OBSERVATION OF THE NEUROSURGICAL PATIENT
}

\author{
NADINE MICHELE ABELSON
}

\section{BSc (NURSING), R.N., R.M., Dip Intensive Nursing, Dip Nursing Education (WITS), Cert Neuromedical and Neurosurgical Nursing (U.K.) \\ Lecturer, Department of Nursing Education, University of the Witwatersrand}

\section{OPSOMMING}

\begin{abstract}
Pasiëntewaarneming is een van die belangrikste funksies van die neurochirurgiese verpleegkundige. Dit behels nie alleen akkurate neem en notering van waarnemings nie, maar ook die intelligente interpretering daarvan om sodoende enige verandering in die pasiënt se toestand te diagnoseer.

Waarnemings in neurochirurgiese verpleging sluit beide neurologiese en algemene waarnemings in. Die belangrikstes en hul implikasies word hier bespreek. 'n Voorbeeld van 'n rekordkaart vir die notering van neurochirurgiese waarnemings, wat ontwikkel is om die gehalte van die waarnemings en pasiëntesorg te verbeter, word ook gegee.
\end{abstract}

\section{INTRODUCTION}

Patient observation is one of the chief responsibilities of the neurosurgical nurse. The nurse is the one and only member of the health team who is with the patient for 24 hours out of every 24 .

Patient assessment is not merely the recording of observations. It requires intelligence, insight and an in-depth knowledge of general anatomy and physiology as well as neuroanatomy, neurophysiology and neuropathology, so that the nurse will be aware of the significance of the observations, and most important, know when to summons medical assistance, based on the observations made

There is no place for time-wasting in neurosurgical nursing. The patient's management and prognosis may depend on the nurse's astute powers of observation and her interpretation of these observations. It is imperative that the findings are assessed and recorded uniformly and accurately in order to be of diagnostic and prognostic value.

Patient observation, both neurosurgical and general, are incorporated into and are one of the most significant features of neurosurgical nursing. The aim of neurosurgical nursing is:

- to promote the physical, mental and social wellbeing of the patient and his family, and

- to ensure that the patient returns to his/her family/community and is able to assume an active role in society once more. The observations that should be carried out on a neurosurgical patient and the significance of these observations are discussed here.

\section{THE IMPORTANCE OF NEU- ROSURGICAL OBSERVA- TION}

What is the importance of neurosurgical observation?

It shows a trend, that is, whether the patient is improving or deteriorating or is in status quo.

The findings aid in the formulation or confirmation of the diagnosis.

Medical treatment is adjusted according to the observations. Early diagnosis and prompt intervention based on observations recorded, may affect patient rehabilitation.

In neurosurgical nursing the patient is regarded as a total person, therefore it is difficult to separate the observations into specific neurosurgical and general observations, especially as many of the observations relate to both neurosurgery and general patient management.

The frequency of patient obser- vation will depend on the patient's condition, the doctor's orders and the sister's discretion. Observations may be performed at $5,10,15.30$ or 60 -minute intervals.

\section{THE IMPORTANT OBSERVA- TIONS}

\section{Level of consciousness}

The level of consciousness may deteriorate because of trauma, pressure, ischaemia and hypoxia to the reticular activating system that is found in the midbrain and brain stem - that part of the brain that keeps us awake. There is no universally accepted method of assessing the level of consciousness, but one of the commonly used methods is that of the Glasgow Coma Scale, although there are many authorities who disapprove of this method, as it is limited.

The Glasgow Coma Scale is scored out of 15 points and subdivided into the following:

eyes opening

best verbal response

best motor response

Total score

A patient's level of consciousness using the Glasgow Coma Scale is assessed as follows: 


\section{EYES OPENING}

\section{4 spontaneously}

that is, when a person enters the patient's room he opens his eyes spontaneously

\section{3 to speech}

the patient opens his eyes to questions such as Please open your eyes

2 to pain the patient only opens his eyes as a result of painful stimulation

1 none

the patient does not respond to any of the above

\section{BEST VERBAL RESPONSE}

\section{5 orientated}

the patient is orientated to time. place and person. It is important to ask the patient questions applicable to his age and intelligence

4 confused

3 inappropriate

the patient gives the incorrect answer to the question asked, such as: examiner what is the time?

patient I play rugby

2 incomprehensible - one cannot understand the patient - he may be mumbling or groaning or swearing (remember that swearing might be appropriate if one is hurting the patient and this is his usual manner of behaviour).

1 none

\section{BEST MOTOR RESPONSE}

6 obeys commands

when the patient is asked to lift his leg he does so

5 localise pain

there is no response to verbal command therefore the nurse tests the patient's response to pain. For instance, she compresses the earlobe or pinches the arm and the patient tries to touch the area that the nurse has tested

\section{4 withdraws}

when the nurse tests the patient's response to pain. the patient withdraws the limb being tested

\section{3 flexion}

on painful stimulation the patient adopts the decorticate position which involves flexion of the arms, wrists and fingers; adduction of the upper extremities; and extension, internal rotation and plantar flexion of the lower extremities. This is a sign of damage in the hypothalamic area and cerebral peduncles.

2 extension

on painful stimulation, the patient adopts the decerebrate position. This involves extension and hyperpronation of the arms; extension and plantar flexion of the lower extremities. This is a sign of pons variola and midbrain disruption.

\section{1 none}

there is no response to painful stimulation.

It must be noted that when testing the patient's response to painful stimulation, it is essential for all the examiners to use the same mcthod of testing to ensure uniform assessment. The patient must not be assaulted when assessing response to pain.

The importance of the Glasgow Coma Scale is that if a patient is examined and on assessment scores 11 out of 15 and 2 hours later scores 7 out of 15 , there is an indication that he is deteriorating. The nurse must summons the doctor, as prompt intervention is imperative.

Other aspects can be included in patient assessment, as the Glasgow Coma Scale only records the patient's best response. Where does one record the worst response?

There are other methods of assessing and recording the level of consciousness. Although appearing to be more simple, they can be misleading, especially to the uninitiated neurosurgical nurse. Another example follows:

5 orientated to time, place and person

4 drowsy but rousable

3 confused

2 responds purposefully to painful stimulation

1 responds non-purposefully to painful stimulation

0 no response.

\section{Pupils}

The pupils may change because of pressure, ischaemia and hypoxia to the 3rd cranial or Occulomotor nerve (parasympathetic). Once this nerve becomes affected, the size, shape and reaction of the pupil changes. Usually the pupil on the side of the lesion is affected first, and thereafter the pupil on the other side. What aspects of pupil observation are important?

\section{Size}

It is important to report a dilating pupil. When the pupils are both fixed and dilated it is an ominous sign. The following must be observed:

- Is the pupil size changing?

- Is the pupil size normal (N)?

- Is the pupil size pinpoint $(\mathrm{P})$ ?

- Is the pupil size small (S)?

- Is the pupil size dilated (D)?

The above method of recording pupil size is simple and accurate.

Pupil size may also be assessed by measuring the actual pupil size against a premeasured set of pupil sizes in millimetres.

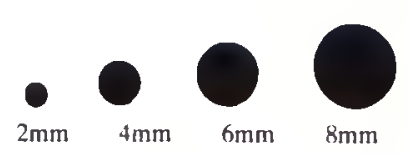

Whatever method of assessing pupil size is used, the important observation is to note any change and call assistance immediately. Remember, however, that certain drugs such as atropine and morphine affect pupil size.

\section{Reaction}

Is the reaction normal $(\mathrm{N})$ ? Is the reaction sluggish (S)? Are the pupils fixed $(F)$ with no reaction?

\section{Equality}

Is the size and reaction of the left pupil equal to that of the right pupil?

Is the left pupil larger than the right?

Is the left pupil smaller than the right?

\section{Shape}

What is the shape of the pupil?

Always bear in mind that the patient may have had a cataract operation/lens impłant, or an eye injury.

\section{Papilloedema}

Is papilloedema present? 
To observe papilloedema an opthalmoscope is required. It occurs when there is engorgement of the retinal vessels and optic disc as a result of raised intracranial pressure and it is best seen in the area of the optic nerve.

\section{Eye movements}

Eye movements may be affected in central nervous system disorders and must therefore be observed. Eye movements are controlled by the following nerves:

3 (Occulomotor nerve)

abnormality results in pupil dilation, ptosis and outward movement of the eye

4 (Trochlear nerve) abnormality results in the affected eye moving inwards

6 (Abucens nerve)

abnormality results in the loss of lateral gaze and diploplia in the affected eye.

As the nurse may not be able to assess Cranial Nerve 3, 4 and 6 function in the unconscious patient she will assess the patient's doll's eye movement which is an occulocephalic response. If one moves the head upwards the eyes move downwards - this is a normal response and doll's eye movement is present.

If, when moving the head to the left or right and up or down, the eyes remain centrally fixed doll's eye movement is absent. This is pathological and must be reported.

\section{Respiration}

Respiration is an important observation, not only from the neurosurgical point of view but also as regards the patient's general condition. An increasing $\mathrm{pCO}_{2}$ causes vessel dilation and causes a further rise in intracranial pressure. This must be prevented, thus observation of the respiratory system is of paramount importance. The patient's respiration may change because of trauma to, pressure on, ischaemia, or hypoxia to the respiratory centres which are found in the Pons variola and Medulla oblongata - the brain stem. The respiratory pattern may vary from midbrain-hyperventilation to irregular breathing to Cheyne Stokes respiration to apnoeic attacks to respiratory arrest.
Injuries that cause changes in respiration are raised intracranial pressure, fractured base of skull and pontine lesions. It is important to remember that the patient's respiration may also change because of chest trauma, aspiration, respiratory failure and respiratory embarrassment.

The following is a list of the observations which must be made regarding respiration:

Airway - is the airway patent? Is there an obstruction (blood, teeth or vomitus) present? A clear airway must be maintained at all times.

Rate - what is the respiratory rate?

Rhythm - is the respiration regular or irregular?

Volume

Air entry - is the air entry equal bilaterally?

Oxygen percentage - controlied $\mathrm{O}_{2}$ must be administered according to blood gases.

\section{Humidification}

Ventilator observations when required.

Pulmonary oedema - with increased intracranial and arterial hypertension there is a redistribution of the blood into the pulmonary vasculature. This causes pulmonary oedema.

\section{Blood pressure}

The blood pressure must be observed as one of the significant features of increasing intracranial pressure is an increase in systolic pressure more than in the diastolic pressure. This drastic increase in systolic pressure occurs in order to overcome the increased intra-cranial pressure by forcing oxygenated blood into the cerebral circulation. This is known as Cushing's law. The systolic pressure, diastolic pressure, and pulse pressure must be noted.

If a neurosurgical patient's blood pressure is dropping he is either

- hypovolaemic, from for example, haemorrhage or diabetes insipidus

- approaching the terminal stage.

Although concerned with neurosurgical observation, the total patient must be observed. The nurse must always be aware of pos- sible haemorrhage and watch for signs of shock.

\section{Pulse Rate}

Some authorities believe that the pulse rate increases then decreases with raised intracranial pressure, others believe that it decreases, as a physiological response to an increased blood pressure. Changes in the pulse rate occur because the cardiac acceleratory centre is affected before the cardiac inhibitory centre - both of which are found in the medulla oblongata. Therefore the patient will develop a tachycardia which may be transient and then a bradycardia or just a bradycardia - both of which are significant.

Besides raised intracranial pressure, a change in pulse rate may be due to shock, hypovolaemia and an acid-base or electrolyte imbalance. The nurse must observe the pulse rate, rhythm, regularity and volume.

In the acute phase, the patient may be attached to a cardiac monitor. Arrythmias that occur from central nervous system disturbances include sinus tachycardia, paroxismal atrial tachycardia and bradyarrythmias from supraventricular and ventricular foci. Lesions that affect the basilar skull, subarachnoid haemorrhage, lesions of the hypothalamus and strokes may present with an inverted $\mathrm{T}$ wave, a prolonged QT interval and prominent $U$ wave (as an anterior myocardial infarction presents) but in this case the enzyme levels are normal.

\section{Haemodynamic status}

The patient's haemodynamic status is also very important. Blood pressure and pulse have been mentioned and the following must also be observed:

- perfusion

- skin colour, temperature and moisture

- fluid intake - oral, nasogastric and intravenous

- fluid output - urine, vomitus, stool, nasogastric and any drainage.

\section{Temperature}

Rectal temperature assessment using a thermocouple is preferable 
as this is most accurate. Damage to the hypothalamus may alter the patient's temperature causing hyper- or hypothermia. Blood in the cerebro-spinal fluid from a subarachnoid haemorrhage or postoperatively will cause a pyrexia, but so will a urinary tract infection or chest infection

\section{Observations for any neuro- logical deficit}

It is important to observe the patient for any neurological deficit by assessing motor, sensory and cranial nerve functions.

\section{Motor function}

When assessing motor function it is essential to assess all four limbs individually and comparatively for position, power, tone and reflexes. Motor function may be affected because of trauma, ischaemia, pressure and oedema or hypoxia to the pyramidal motor tract that commences in the Betz cells of the motor cortex in the area of the precentral gyrus, and passes through the internunceal neurone to the anterior motor fibre that supplies the various muscles. To simplify the recording of motor function the various aspects of motor function can be coded, as shown below.

\section{POSITION}

3 Normal - when one examines the patient the limbs are in a normal position

2 Decorticate - the arms are flexed, the limbs are extended

1 Decerebrate - the arms and legs are extended

POWER is coded according to the internationally accepted method of assessing power (Bannister Sir R. 1978 p. 19)

5 Normal - on testing the power is found to be normal

4 Reduced - on testing the power is found to be decreased but there is some power present

3 Gravity + - the patient is able to lift his arm/leg against gravity

2 Gravity- - patient is able to move his limb if the force of gravity is removed by the examiner supporting the limb

0 None - there is no movement
TONE is coded as

3 Normal

2 Increased

1 Decreased

\section{Sensory function}

A neurological deficit may not be motor but may involve sensory pathways, and therefore the patient's sensory function must be assessed. When assessing sensation the nurse must assess general sensation such as:

pain

temperature

course touch

fine touch

proprioception - joint position sense

as well as specific sensation

vision

speech

hearing

smell

taste.

\section{Cranial nerve function}

This must also be assessed to detect any deficit, such as bulbar palsy (absence of coughing and swallowing), facial palsy.

\section{Raised intra-cranial pressure}

The patient must be assessed for any signs and symptoms of raised intra-cranial pressure. Some of these have been discussed already:

level of consciousness

pupils

blood pressure

pulse

respiration

papilloedema

and others include:

nausea and vomiting

headache

visual disturbances, photophobia.

The nature, duration, severity and position of any headache must be noted, as well as the relationship between headache, nausea and vomiting. The type and frequency of vomiting must also be recorded and reported.

Convulsions, seizures and fits are important and must be recorded. Remember that a seizure may be motor or sensory depending on the area involved. The following must be noted:

any predisposing factors type of seizure

generalised seizure

focal seizure

duration

the progression of the seizure incontinence

cyanosis

pupil responses.

\section{Cerebro-spinal fluid leakage}

Cerebro-spinal fluid leakage is very significant. Cerebro-spinal fluid may leak from the ears, nose and throat as well as from wounds and intra-ventricular drainage or monitoring circuits. The danger of cerebro-spinal fluid leakage is that of infection and air entry. A cerebrospinal fluid leak can be recognised by the following:

\section{the patients signs and symptoms}

- he complains that when he stoops, lifts anything heavy, or gets out of bed, his nose runs

- he complains of a salty taste in his mouth

- he mentions that he has been in an accident or a fight in which his nose was injured or broken - there may be damage to the ethmoid and cribriform plate

- he has recurrent attacks of meningitis after a fractured base of skull

the appearance of the cerebro spinal fluid

- like an egg yolk and an egg white the red blood cells and cerebro spinal fluid separate. This is noticed on the pillow case or absorbent sheet on which the patient is resting his head

biochemistry of the cerebro-spinal fluid

ph: alkaline

sugar: positive (normal value 3.54,5 mmol per litre)

protein: positive (normal value 0.15-0.45 gm per litre)

A cerebro-spinal fluid leakage is very dangerous and therefore must be reported immediately. It must not be plugged, but kept covered with a sterile pad and treated aseptically. 


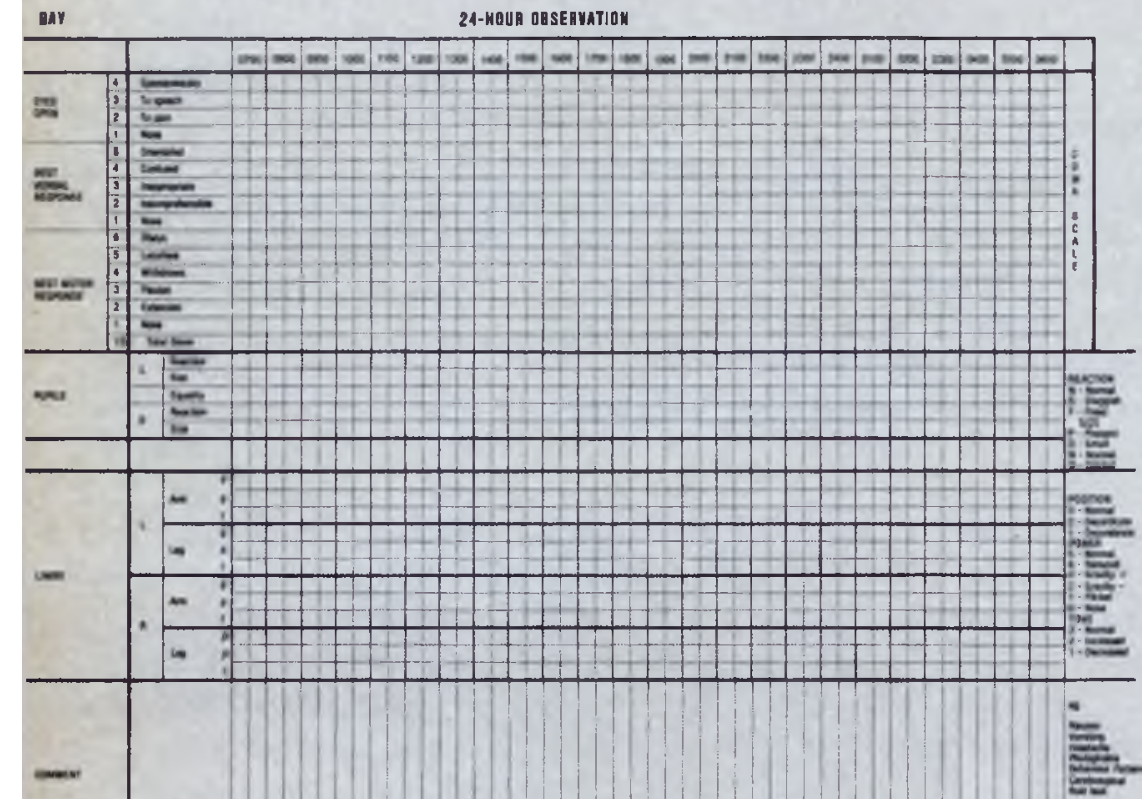

$=$

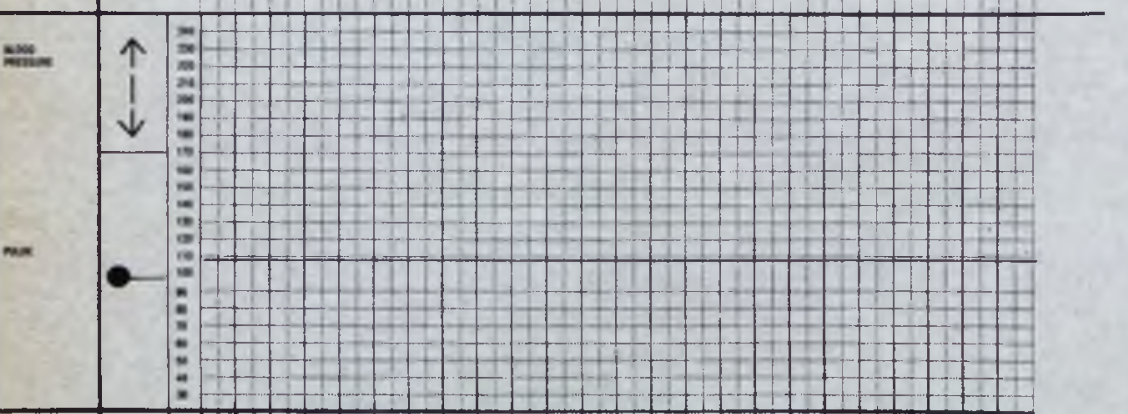

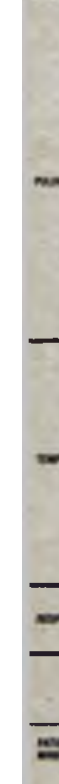




\section{Behaviour patterns}

Behaviour patterns may also give an indication of cerebral pathology and must therefore be observed.

Mood - does the patient have frequent alterations in mood, perhaps euphoria, aggression or depression Personality - has there been a personality change?

Intellect - has his intellect changed? What about intelligence and powers of concentration?

Memory - can he remember recent events? past events?

Activities and socialisation patterns - is his behaviour acceptable?

There are often personality, mood and behaviour changes in frontal lobe pathology.

\section{Intra-cranial pressure moni- toring}

This is extremely important but is only done in specialised units where there are adequate resources. The intra-cranial monitoring device may be placed in the lateral ventrical, sub-durally or extradurally. The following is noted:

systolic pressure

diastolic pressure

mean pressure.

The intra-cranial pressure should be kept below $25 \mathrm{~mm} \mathrm{Hg}$ (normal value $10-15 \mathrm{~mm} \mathrm{Hg}$ ). The nurse must be aware of any patient intervention that will cause an increase in intra-cranial pressure, such as hurting the patient, suctioning the patient, taking arterial blood gases or causing interference with cerebral venous drainage by malpositioning the head and neck or nursing the patient in the head-down position.

\section{General observation}

Not only must the patient's neurological state be assessed, but all sys- tems must be checked. General observation will include:

- the patient's psychological state

- the skin - abrasions, bruising, decubitus ulcers and allergies

- state of hydration - the urine output must be measured because it may be an indication of one of the following:

- diabetes insipidus after head injury or with a pituitary lesion or operation

- decreased fluid intake - due to nausea and vomiting, lethargy or unconsciousness

- inappropriate A.D.H. secretion after head injury

- haemodynamic disturbances or renal complications

- nutritional state

- reaction to drugs

- reaction to stimulation and motivation

- the condition of the eyes, nose and mouth regarding ulceration, infection or any other complication

- the results of investigations. (One must therefore know the normal values to be able to report when a result is abnormal)

\section{RECORDING AND ASSESS- MENT OF OBSERVATIONS}

Assessment of the neurosurgical patient involves time, patience and intelligent observation. The patient's length and quality of life might depend on the neurological nurse's findings and therefore she must be familiar with all the abovementioned observations and their significance. The nurse must be aware of the importance of summoning medical assistance as soon as the observations change.

There is no universally accepted method of assessing and recording neurosurgical observations but, in an endeavour to improve the standard of neurosurgical patient observation and management, a concise patient management plan has been produced. This enables accurate patient assessment and uniform recording of the findings. The chart provides for recording of observations for a 24-hour period at halfhourly to hourly intervals enabling one to see a trend in the observations. There is a guideline and key to recording on the chart which is used by all members of the health team, not only nursing staff. The chart is illustrated in figure 1 on page 36 .

This is an important advancement in neurosurgical nursing, not only for patient management and rehabilitation, but also for the purpose of teaching and research as well as medico-legal enquiries.

\section{SUMMARY}

In summary the following important points:

\section{Assess accurately \\ Observing \\ Charting \\ Chart legibly \\ Understandably \\ Note the trend of findings \\ Call for medical intervention}

BIBLIOGRAPHY

Bannister. Sir R Brain's clinical neurology

Oxford Medical Publications New York 1978 5th ed

Bickerstaff. Edwin R Neurology Hodder and Stoughton London 1978

Davis,Joan E; Mason, Celestine B Neurological crifical care Van Nostrand Reinhold New York 1979

Jennett, W Bryan An introduction to neurosurgery William Heinemann Medical Books London 1970 2nd ed Purchese, Gillian Neuromedical and neurosurgical nursing Nursing Aid Series Bailliére Tindall London 1977

Schmidt, Robent $F$ Fundamentals of neurophysiology Springer-Verlag New York 1978 2nd ed. 